\title{
ANÁLISE DE CLIMA ORGANIZACIONAL EM EQUIPES DE TRABALHO NA GESTÃO PÚBLICA DO GOVERNO DE MINAS GERAIS
}

\author{
Renato Rodrigues da Silva ${ }^{1}$ \\ Ruan Carlos dos Santos ${ }^{2}$ \\ Alexandre Oliveira Lima $^{3}$ \\ Leonel Gois Lima Oliveira ${ }^{4}$
}

\section{RESUMO}

Objetivo do estudo: A percepção sobre o clima organizacional é uma das variá veis que diferencia as empresas com uma boa gestão de pessoas, daquelas que fazem das pessoas meros recursos necessários para geração de lucro. Tais pesquisas são pouco desenvolvidas no setor público. A pesquisa se justifica pela possibilidade de apontar as variáveis que afetam o clima organizacional, bem como, a satisfação dos servidores públicos pertencentes a o grupo estudado. Originalidade/Relevância: Este estudo está entre os primeiros do setor público a demonstrar a importância do clima orga niza cional para o desempenho criativo individual dos funcionários. As conclusões deste estudo acrescentam ao nosso conhecimento e compreensão atuais do valor do clima organizacionale sua influência sobre o desempenho criativo individual no setor público.

Metodologia: A metodologia é uma pesquisa descritiva, usando para isso a pesquisa bibliográfica e estudo de caso numa abordagem quantitativa. Usou como instrumento um questionário online e a observação direta participante. Principais resultados: Foi identifica do o perfil dos servidores bem como as dimensões: Estrutura e a mbiente físico; cooperação e reciprocida de no a mbiente de trabalho; participação nas decisões; reconhecimento de mérito; identificação com a instituição; controles; autonomia funcional; conflitos; remuneração e oportunidade; perspectiva na instituição que interferem na percepção do clima organizacional pelos servidores obtendo 99 respostas. Os objetivos foram alcançados e notou-se a necessidade de implantar e desenvolver algumas políticas de recursos humanos para sobretudo valorizar o capital intelectual existente dentro de cada órgão. Contribuições teóricas: A pesquisa contribui demonstrar a necessidade das empresas públicas e criarem políticas sobre o clima organizacional entre uma ligação positiva e significativa com as duas variáveis de desempenho criativo incluídas neste estudo. Além disso, o estudo revelou que o indivíduo criativo modifica a relação entre o clima organizacionale o comportamento inova dor individual.

Palavras-chave: Clima Organizacional. Percepção. Setor Público.

Submetido em: 11/01/2021

Aprovado em: 15/03/2021

DOI: https://doi.org/10.37497/revcampojur.v9i1.663

\footnotetext{
1 Doutorado em Geologia pela Universidade de Freiburg, Alemanha. do Departamento de Geologia/IGC/UFMG, Minas Gerais. Email: renatosilva@ufmg.br Orcid:https://orcid.org/0000-0003-2153-6333

2 Doutorando em Administração pela Universidade do Vale do Itajaí, UNIVALI, Santa Catarina (Brasil). Email: ruan_santos1984@hotmail.com Orcid:http://orcid.org/0000-0001-7396-8774

3 Doutor em Administração de Empresas pela Universidade de Fortaleza, UNIFOR. Professor Adjunto da Universidade da Integração Internacional da Lusofonia Afro-Brasileira - UNILAB, Ceará (Brasil). Email: alexandrelima@unilab.edu.br Orcid:https://orcid.org/0000-0002-8878-7965

4 Doutorado em Administração pela Fundação Getúlio Vargas, Rio de Janeiro. Professor de graduação e pósgraduado do Centro Universitário Christus (UNICHRISTUS), Ceará (Brasil). Email: leonelgois@gmail.com Orcid: https://orcid.org/0000-0003-3876-5028
}

\section{Campo Jurídico|Barreiras (BA)| v.9 |e663| p.01-30 |Janeiro-Junho|2021}




\title{
ORGANIZATIONAL CLIMATE ANALYSIS IN WORK TEAMS IN THE PUBLIC MANAGEMENT OF THE GOVERNMENT OF MINAS GERAIS STATE
}

\begin{abstract}
Purpose: The perception about organizational climate is one of the variables that differentiate companies with good people management, from those that make people mere resources needed to generate profit. Such researches are little developed in the public sector. The research is justified by the possibility of pointing out the variables that affect the organizationalclimate, as well as the satisfaction of the public servants be longing to the group studied. Originality/Relevance: This study is among the first in the public sector to demonstrate the importance of the organizational climate for the individual creative performance of employees. The findings of this study add to our current knowledge and understanding of the value of organizational climate and its influence on individual creative performance in the public sector. Methodology: The methodology is a descriptive research, using literature search and case study in a quantitative approach. It used as an instrument an online questionnaire and direct participant observation. Main results: The profile of the servers was identified, as well as the dimensions: structure and physical environment; cooperation and reciprocity in the work environment; participation in decisions; merit recognition; identification with the institution; controls; functional autonomy; conflicts; remuneration and opportunity; perspective in the institution that interfere in the perception of the organizational climate by the servers, obtaining 99 answers. The objectives were achieved and it was noted the need to implement and develop some human resources policies to especially value the intellectual capital existing within each organ.Theoretical contributions: The research contributes demonstrate the need for public companies and create policies on organizational climate between a positive and significant link with the two variables of creative performance included in this study. In addition, the study revealed that the creative individual modifies the relationship between orga nizational climate and individual innovative beha vior.
\end{abstract}

Keywords: OrganizationalClimate. Perception. Public Sector.

\section{INTRODUÇÃO}

As organizações atualmente convivem com desafios de diversas naturezas dentre eles os novos perfis de clientes, os econômicos, políticos e ambientais além da competitividade existente no mercado e na sociedade. Para enfrentar tantos desafios impostos, as empresas têm revistos seus modelos de gestão, buscando evoluir seus procedimentos para maximizar os resultados do processo produtivo. Para o alcance de resultados observa-se que a busca por melhores indicadores de desempenho, reforçam a necessidade de repensar as práticas e métodos de gestão de forma favorecer melhor o posicionamento do negócio em sua área de atuação (NOBREGA; SÁ; 2010).

Além dos desafios que são próprios das organizações modernas observa-se que o mundo está mudando muito rapidamente com uma intensidade cada vez maior. A mudança não é algo específico dos tempos atuais, mas a velocidade, suas repercussões nas empresas bem como o volume ocorrido atualmente são próprias dos dias de hoje.

Diversos fatores contribuem para as transformações sendo que dentre eles pode-se enumerar as mudanças tecnológicas, políticas, culturais, sociais e legais além das variações no padrão econômico e demográfico. Esses fatores contribuem para trazer para dentro das empresas insegurança e criando um clima duvidoso para todos envolvidos, sejam eles funcionários, acionistas, líderes, forneced ores e governo (CHIAVENATO, 2004).

É nesse contexto de incertezas e a necessidade de se preparar melhor para os desafios que surgem que desaponta a preocupação com a gestão das pessoas dentro das organizações. As pessoas aplicam seus conhecimentos, habilidades e atitudes necessárias para que o negócio aconteça de forma sustentável e competitiva na tentativa de corresponder às expectativas dos stakeholders (públicos de relacionamento). 
Segundo Chiavenato (2004, p. 4) “[...] as pessoas passam a significar o diferencial competitivo que mantém e promove o sucesso organizacional [...]". Ainda para o autor, são as pessoas as responsáveis pelo sucesso das empresas. Essa visão apesar de ser colocada de forma simplista, na prática é capaz de gerar profundas discussões no que diz respeito às relações de trabalho e ao próprio comportamento humano.

Além disso, Teixeira (2010), ressalta a importância de repensar a gestão de pessoas, mudando a atual concepção técnico-funcional para uma gestão estratégica onde os funcionários agregam valor as empresas e são considerados diferenciais competitivos.

Nesta perspectiva considerando que sucesso organizacional em grande parte depende das pessoas, Araújo e Garcia (2010) afirmam que os funcionários colaboram para instalação de um clima de organizacional favorável que é capaz de gerar resultados sejam eles para o negócio ou para as atividades da empresa.

A percepção sobre o clima organizacional é uma das variáveis que diferencias as empresas com uma boa gestão de pessoas, daquelas que fazem das pessoas meros recursos necessários para geração de lucro. Além disso, segundo Paula (2011), as pessoas colaboram mais com a organização, trabalham em prol do atingimento de resultados empresariais, e tem maior participação nas decisões além de trabalharem melhor em equipe quando o clima é agravável. Muitas organizações não se debruçam sobre a análise do clima organizacional de suas empresas de tal forma que ignoram que o clima pode afetar positivamente ou negativamente os resultados por ela gerado.

Normalmente se fala com maior expressividade em pesquisa de clima organizacional em instituições privadas, pelo menos a mais tempo do que nas organizações públicas. Para entendermos melhor na prática como o clima organizacional é percebido em setores públicos, o grupo alvo dessa pesquisa é composto de servidores da Secretaria de Estado de Saúde (SES) e Secretaria de Estado de Planejamento e Gestão - (SEPLAG), ambos órgãos da administração direta do Governo do Estado Minas Gerais. A SES tem como missão: formular, regular e fomentar as políticas de saúde de Minas Gerais, de acordo com as necessidades da população, assegurando os princípios do Sistema Único de Saúde (SUS). ${ }^{5}$ Já a SEPLAG tem como objetivo: coordenar, formular, executar e avaliar políticas que visem o desenvolvimento econômico, social e institucional de Minas Gerais (SEPLAG, 2015).

A pesquisa se justifica pela possibilidade de apontar as variáveis que afetam o clima organizacional bem como a satisfação dos servidores públicos pertencentes ao grupo estudado. Uma pesquisa dessa natureza ainda não foi realizada em um dos setores da SES enquanto estava à frente da equipe, segundo uma gestora. No segundo local alguns membros da equipe passaram recentemente pela pesquisa clima organizacional conduzido por uma empresa contratada pela empresa Abril no âmbito do programa "Participação na Pesquisa Melhores Instituições Públicas para você trabalhar 2014”.

Nesta perspectiva, este trabalho tem por objetivo geral, analisar a percepção de servidores públicos de 3 setores diferentes ligados a Administração Direta do Governo de Minas Gerais quanto às variáveis que afetam de forma positiva e negativa o clima organizacional. Os objetivos específicos deste trabalho são:

- Mapear o perfil da amostra selecionada;

- Identificar quais variáveis tem melhor e pior avaliação na percepção do clima organizacional pelos servidores;

- Propor de forma resumida propostas de solução ou de melhoria que afetariam de forma positiva a percepção do clima organizacional pelos servidores;

${ }^{5}$ Extraído na íntegra do Plano Estadualde Saúde - 2008 - 2011. Site institucional da SES. 


\section{REFERENCIAL TEÓRICO}

A temática clima organizacional começou a ser estudada no Brasil na década de 70 e cabe destaca-se o trabalho realizado por Edela Lanzer Pereira de Souza (1978) com a publicação do livro: "Clima e cultura organizacionais: como se manifestam e como se manejam". Segundo essa autora clima e cultura organizacional estão relacionados de forma que existe uma relação de causalidade circular entre clima e cultura.

Ambos têm efeito sobre os resultad os da empresa podendo ser positivos ou negativos. Mesmo com a relação de causalidade, ou seja, o clima afeta a cultura e a cultura afeta o clima, existem outras variáveis que impactam no resultado das organizações. Uma variável que é externa a cultura e clima, mas que interfere no resultado seria os problemas sociais, familiares e pessoais dos trabalhadores que afetam, por exemplo, sua motivação para o trabalho (SOUZA, 1978 apud LUZ, 2003) $)^{6}$. Nos tópicos a seguir, é feita uma breve contextualização da temática Gestão de Pessoas e sobre o objeto específico desse trabalho que é sobre clima organizacional.

\subsection{Gestão de Pessoas}

\subsubsection{Os desafios da gestão de pessoas na contemporaneidade}

Antes de explorar a temática gestão de pessoas é preciso ter bem claro os principais conceitos ligados a administração e gestão. Gestão é um conceito ligado a administração e é "um conjunto de esforços que tem por objetivo: planejar, organizar, dirigir ou liderar; coordenar e controlar as atividades de um grupo de indivíduos que se associam para atingir um resultado comum" (LACOMBE, 2004 apud GARCIA; ARAUJO, 2010, p. 1) ${ }^{7}$.

A área de GP dentro das organizações começou de forma muito incipiente, ou seja, muito amadora quando a comparamos com a atual área de gestão de recursos humanos (RH). É importante salientar que em sua origem seu objetivo foi cumprido, acontece que ao longo dos anos as necessidades relacionadas a área de pessoas foi tornando-se mais complexa e desafiado. No Brasil e no mundo, a demanda era pela contabilização dos registros dos funcionários no que diz respeito a horas trabalhadas, ausências e atrasos e o objetivo era mensurar o valor correto de salário que deveria ser pago aos funcionários pelo trabalho prestado. Alguns estudiosos consideram que essa fase no Brasil foi até 1930, sendo que a partir daí a abordagem mud ou (MARRAS, 2011; GARCIA; ARAUJO, 2010).

Com a publicação do Decreto Lei 5.452/1943 que aprovava a Consolidação das Leis do Trabalho (CLT) o papel da área de gestão de pessoas teve que se adaptar uma vez que a partir desse momento era necessário seguir uma série de práticas administrativas conhecidas como rotinas trabalhistas. As atividades que eram desempenhadas pelos chefes da produção passaram a ser feitas pelo chefe de pessoal uma vez os processos de recrutamento, seleção, treinamento, admissão, demissão e pagamento deveriam ser realizados a partir do cumprimento da referida legislação. Cabe ressaltar que nessa fase, dada a necessidade de ser entender a legislação trabalhista, os chefes de pessoal eram advogados ou bacharéis em Direito, sendo que esse ramo do conhecimento foi responsável pela área de pessoas até o final da década de 70 (MARRAS, 2011; GARCIA; ARAUJO, 2010).

A partir de um movimento renovador que surgiu principalmente nos Estados Unidos, a fase denominada tecnicista visava implantar no Brasil um modelo de gestão americano de pessoal e fez com que a função de RH tivesse o status de gerência dentro das organizações.

\footnotetext{
6 SOUZA, Edela Lanzer Pereira de. Clima e cultura organizacionais: como se manifestam e como se manejam. São Paulo: Edgar Blucher, 1978.

${ }^{7}$ LACO.........
}

\section{Campo Jurídico|Barreiras (BA)| v.9 |e663| p.01-30 |Janeiro-Junho|2021}


Neste mesmo período o Brasil passava por expansão no seu setor automobilístico. Ressalta-se que nessa implantação algumas modificações tiveram que ser feitas no sentido de se adaptar as características locais de gerenciamento e da própria cultura organizacional. Esse período, chamado por alguns autores de tecnicista foi de grande avanço para a relação que se estabelece entre empregado e empregador. A área de RH se organizou passando a executar o que hoje denomina-se subsistemas de RH: recrutamento e seleção, treinamento, cargos e salários, higiene e segurança, benefícios dentre outros. Por último, destaca-se que nesta fase foi notado em grande parte das empresas a figura do Gerente de Relações Industriais (GRI) que cuidava dos aspectos puramente administrativos (MARRAS, 2011; GARCIA; ARAUJO, 2010).

Surge a partir de 1965 a fase considerada como administrativa. Essa fase é destacada pelo fortalecimento do movimento sindical que marcava a relação entre trabalho e capital no movimento chamado "novo sindicalismo". O que de mais importante deve se destacar nesta fase foi a concepção do que o GRI deveria ser responsável. Se antes sua atuação se dava no campo dos aspectos burocráticos e puramente operacionais, a partir desse movimento que ganhava força tanto no Brasil quanto no mundo, sua ênfase deveria ser mais nas questões de ordem humanística orientada para os indivíduos e suas diversas relações, tais como: sociedade e sindicato (MARRAS, 2011; GARCIA; ARAUJO, 2010; PRIYANKARA; LUO; SAEED; NUBUOR; JAYASURIYA, 2018).

Por último, e bem próximo dos dias de hoje, a partir de 1985 observa-se a fase estratégica, que foi marcada pelo planejamento estratégico das empresas, a visão de longo prazo e suas relações com as pessoas. Mais uma vez o RH passa a ter uma posição de destaque deixando de ser apenas uma gerência, como era principalmente na fase tecnicista para uma área ligada a diretoria, ou seja, no nível mais estratégico (MARRAS, 2011; GARCIA; ARAUJO, 2010).

A partir do entendimento que o RH ocupa uma posição estratégica nas organizações atualmente é importante entender o ambiente em que se opera a gestão de pessoas. Para esse entendimento Teixeira, et al (2010) faz uma análise a partir de três dimensões, a saber: mundo de negócios, mundo do trabalho, e cultura e clima organizacional. Segundo os autores essas dimensões refletem as diversas mudanças ocorridas na contemporaneidade no mundo e que acabam por afetar o contexto empresarial tais como: culturais, políticas, tecnológicas e sociais (CHUANG; DILL; MORGAN; KONRAD, 2012)

A primeira dimensão: mundo dos negócios, leva em consideração as principais variáveis que atuam no contexto organizacional de forma bem acelerada. O primeiro destaque é dado para a sociedade do conhecimento onde o capital humano sobressai. Segundo Davenport e Pruzak (1998, p. 20) ${ }^{8}$, apud Teixeira, et al (2010, p. 40), "ao contrário dos ativos materiais, que diminuem à medida que são usados, os ativos do conhecimento aumentam com o uso [...]". A partir dessa perspectiva observa-se uma mudança nas empresas que estão deixando de ser intensas em mão de obras, ou seja, trabalhador manual tradicional, para trabalhador do conhecimento.

O segundo destaque é para a sociedade da informação que se fortalece tendo como base a dimensão digital. Essa variável leva as empresas enfatizarem com o discurso de manutenção da competividade, o e-business e a gestão de pessoas, a e-GP. Teixeira, et al (2010, p.41), considera que a e-GP é: "uma estratégia que, utilizando meios digitais e tecnologias de rede, agiliza e otimiza os serviços para seus clientes: gerentes e colaboradores". E mais: "com ênfase na e-GP, a gestão de pessoas abandona a abordagem do

8 DAVENPORT, Thomas H.; PRUZAK, Laurence. Conhecimento empresarial: como as organizações gerenciam seu capital intelectual. Rio de Janeiro: Campus, 1998.

Campo Jurídico|Barreiras (BA)| v.9 |e663| p.01-30 |Janeiro-Junho|2021 
isolamento do antigo departamento pessoal e passa a atuar de forma interativa e online com os parceiros das demais unidades da empresa".

Por último a hipercompetitividade tem influenciado a GP através de privatizações, flexibilidade de monopólios, fusões e aquisições e crescimento das empresas multinacionais. Ela é capaz de elevar a velocidade das mudanças e exigir respostas dinâmicas e tempestivas (TEIXEIRA, et al, 2010).

A segunda dimensão que é o mundo do trabalho é ampla e nela estão elencadas diversas variáveis existentes hoje no contexto empresarial, a saber:

$\checkmark$ convive-se com a crescente convivência do emprego clássico com um novo tipo de emprego onde há possibilidade de trabalho para mais de um empregador, distantes dos habituais prédios da empresa e em regimes mais flexíveis;

$\checkmark$ nota-se gradual desconfiguração do cargo em sua forma tradicional onde cada um tem tarefas específicas para um modelo onde há diversificação no grupo de tarefas a serem desenvolvidas;

$\checkmark$ base tecnológica mais sofisticada que originou a criação de cargos que exigem maior qualificação;

$\checkmark$ migração do emprego fazendo com que a empresa continue no país onde estão sediadas e os empregos migrem;

$\checkmark$ novas formas de flexibilização do trabalho que vão desde a contratação, duração e as formas de organização do trabalho. Ainda sobre as formas de organização do trabalho ressalta-se que no atual contexto há a presença de equipes interdisciplinares, cargos compartilhados, teletrabalho e multifuncionalidade (TEIXEIRA, et al, 2010).

Por último os autores relatam sobre clima e cultura organizacional que são tratados no próximo tópico desse trabalho. Cabe ressaltar que o atual contexto em que se opera a gestão de pessoa é desafiador. Segundo Vergara (2012), a complexidade do mundo contemporâneo está relacionada com a era da informação e a própria globalização, as forças e fraquezas do modelo de desenvolvimento além do surgimento de novos valores pessoais e a emergência de um novo paradigma.

Para dar a resposta a esses grandes desafios que interferem diretamente na gestão de pessoas, além disso para lidar com uma realidade cheia de inseguranças e incertezas existem algumas atividades que são essenciais nesta área. Existem diversas subdivisões nessas atividades que de tão específicas não deixam de promover o fortalecimento da área como um todo (GARCIA; ARAUJO, 2010).

\subsubsection{Os subsistemas da área de gestão de pessoas}

Dentre as diversas subdivisões da área temos o processo de recrutamento e seleção que se relaciona com a atividade de identificar e atrair candidatos para serem submetidos ao processo de seleção que leva consideração a utilização de ferramentas (entrevistas, aplicação de provas e testes, dinâmicas de grupo, simulação e exames) para selecionar aqueles candidatos que irão ocupar uma vaga na organização. É esse grupo de atividades também responsável por mensurar o índice de rotatividade bem como de trabalhar com banco de dados relativos a candidatos participantes de processos seletivos na empresa (MARRAS, 2011; GARCIA; ARAUJO, 2010).

A área de cargos e salários é responsável pela administração de cargos, de salários, benefícios e pesquisas de mercado. Essa área deve estar sempre atenta as práticas de remuneração da empresa bem como do mercado a afim de garantir o equilíbrio e a 
sustentabilidade da prática salarial. Faz parte do grupo de atividades dessa área estruturação de plano de cargos, carreiras e salários (MARRAS, 2011; GARCIA; ARAUJO, 2010).

Observa-se também o trabalho realizado pela área de treinamento e desenvolvimento (T\&D) que através dos processos educacionais que visam basicamente no caso do treinamento o condicionamento da pessoa para o cargo atual; já o desenvolvimento é orientado para o crescimento da pessoa em nível de competência (conhecimento, habilidade e atitude). São etapas importantes do processo de T\&D o diagnóstico, planejamento, implementação e avaliação (MARRAS, 2011; GARCIA; ARAUJO, 2010).

Além das principais atividades relacionadas a Gestão de pessoas já citadas temos ainda a gestão do desempenho que busca medir, mensurar o conjunto de entregas e resultados de determinada pessoa para a empresa ou negócio; a gestão de benefícios sociais compõe a remuneração indireta que as organizações proporcionam ao colaborador, além disso os benefícios na maior parte deles de natureza assistencial faz parte da estratégia das empresas na retenção de seus talentos; a área de segurança e saúde do trabalho é regida prioritariamente pela legislação e seu funcionamento também é fiscalizado de perto pelos órgãos competentes (MARRAS, 2011; GARCIA; ARAUJO, 2010).

Dentro de toda plataforma que envolve a gestão de pessoas encontramos a temática clima organizacional, muito ligada a cultura organizacional que pode ser conceituada como:

Um padrão de pressupostos básicos inventados, descobertos ou desenvolvidos por um determinado grupo, à medida que ele aprender a lidar com seus problemas de adaptação externa e integração interna, e que funcionou bem o suficiente para ser considerado válido e ser ensinado a novos membros como uma forma correta de perceber, pensar e sentir em relação àqueles problemas (SHEIN, 1992 apud GARCIA; ARAUJO, 2010, p. 285 $)^{9}$.

A cultura organizacional se divide em valores que são definidos como:

crenças e valores que moldam o contorno cultural de grupo, estabelecendo padrões de comportamento, de avaliação e de imagem. Em uma organização, o sistema de valores baliza e demonstra claramente quais as prioridades e os caminhos que a empresa normalmente deseja seguir na busca de seus objetivos (MARRAS, 2011, p. 293).

Ainda se divide em ritos que "são praticados com a finalidade de perpetuar, no dia a dia, os valores organizacionais e tornar a cultura mais coesa" conforme Marras (2011, p. 294). Esse autor divide ainda os ritos como de passagem (celebrações que levam em consideração a mudança de uma situação para outra); e iniciação (identificam momentos de entrada em determinadas situações ou grupos).

Os mitos, outra divisão existente na cultura organizacional, são formados a partir de figuras imaginárias e fatos não concretos e são usadas para reafirmar crenças da organização mantendo o valor histórico presente.

Já os tabus decorrem do processo cultural e tem a função de orientar as atitudes e comportamentos e o foco é nas proibições e coisas que não são bem vistas dentro da organização (GARCIA; ARAUJO, 2010).

A cultura organizacional está mais relacionada aos elementos próprios que constituíram aquela organização e de um modo geral servem para orientar comportamentos.

No capítulo seguinte, apresentam-se os conceitos relativos a clima organizacional, objeto específico desse trabalho.

\subsection{Clima Organizacional}

Os estudos sobre clima organizacional foram iniciados em 1927 com o experimento de Elton Mayo intitulado Experimento de Hawthorne. $O$ pesquisador constatou que

9 SCHEIN, Edgar H. Organization culture and leadership. São Francisco: Jossey Bass, 1992.

Campo Jurídico|Barreiras (BA)| v.9 |e663| p.01-30 |Janeiro-Junho|2021 
"modificações nas configurações física e social do ambiente de trabalho podem provocar mudanças emocionais e comportamentais significativas nos trabalhadores, como fadiga, acidentes de trabalho, turnover, e redução no desempenho e produtividade". Doze anos depois desse estudo ter sido realizado, Kurt Lewin que era estudioso da teoria do campo começou a divulgar seus trabalhos. Em 1939 este autor fala sobre o conceito de campo vital, nesta teoria “as atividades psicológicas de um sujeito ocorrem numa espécie de campo psicológico o qual compreende todos os eventos passados, presentes e futuros que podem influenciar o comportamento de uma pessoa em determinada situação". (GOMES; MENEZES, 2010, p.160).

Estes estudos ao longo desses anos serviram de base para que Lewin, Lippitt e White em 1939 fizessem um estudo para observar quais eram as condições psicológicas proporcionadas pelos líderes de grupo de jovens num ambiente controlado. As conclusões dos pesquisadores passam pela importância de se investigar os elementos culturais para entender os ambientes complexos, tais como as organizações. Esses conceitos e teorias foram sendo divulgados após a Segunda Guerra Mundial com a Escola das Relações Humanas. Esse movimento vinha se opor ao que Taylor em 1911 havia postulado com a Administração Científica (GOMES; MENEZES, 2010).

Somente em 1958 com os trabalhos realizado por Argyris que a concepção de clima organizacional passou a ser chamada por esse nome. No trabalho realizado por Argyris conhecer o clima organizacional "implicaria, assim, investigar fatores individuais, associados diretamente aos valores, necessidades e tipos de personalidade dos indivíduos, bem como em analisar as políticas, normas e códigos que representam a cultura da organização". Nos estudos feitos por Argyris há uma vinculação a noção de clima do conceito de cultura organizacional e isso faz com que o conceito de clima fique pulverizado dificultando uma definição única do assunto (GOMES; MENEZES, 2010).

$\mathrm{Na}$ literatura encontra-se alguns conceitos para clima organizacional. Luz (2003), traz alguns desses conceitos em seu livro: Gestão do Clima Organizacional.

D. J. Champion considera clima como:

Pode-se definir clima organizacional como sendo as impressões gerais ou percepções dos empregados em relação ao seu ambiente de trabalho; embora nem todos os indivíduos tenham a mesma opinião, pois não tem a mesma percepção, o clima organizacional reflete o comportamento organizacional, isto é, atributos específicos de uma organização, seus valores ou atitudes que afetam a maneira pela qualas pessoas ou grupos se relacionam no seu ambiente de trabalho. (CHAMPION, apud LUZ, 2003, p10) $)^{10}$

Champion faz menção ao comportamento organizacional assim como Litwin apud Luz (2003, p.10), que define como clima organizacional: “[...] é a qualidade ou propriedade do ambiente organizacional, que é percebida ou experimentada pelos membros da organização e influencia o seu comportamento".

Ambos os autores citam a questão do comportamento e de fato esse atributo faz parte do clima e se relaciona com o conceito de cultura organizacional principalmente quando se entende que o clima é capaz de influenciar o comportamento dos sujeitos.

Luz (2003, p. 12) ainda elabora o seguinte conceito para clima: “[...] é o reflexo do estado de ânimo ou do grau de satisfação dos funcionários de uma empresa, num dado momento". Para o autor, clima organizacional é a atmosfera psicológica que envolve, num dado momento, a relação entre empresa e seus funcionários.

O conceito de clima organizacional é transversal e em suas definições encontramos três aspectos que merecem a atenção e análise sendo eles: satisfação e percepção dos

$10 \mathrm{O}$ texto não fez referência a obra na qual foi extraído o conceito.

Campo Jurídico|Barreiras (BA)| v.9 |e663| p.01-30 |Janeiro-Junho|2021 
funcionários e cultura organizacional. A satisfação tem relação direta ou indireta com o clima e sobre ela notamos o grau de satisfação das pessoas que trabalham em uma organização. A percepção relaciona-se com aspectos da empresa que podem influenciar os colaboradores de maneira positiva ou negativa, "portanto, se os funcionários percebem a empresa positivamente, o clima dessa empresa tende a ser bom; ao contrário, se eles percebem mal a empresa, o clima tende a ser ruim". Já a cultura é tratada por alguns autores como sendo um conceito similar ao de clima e o que se tem claro hoje é que a cultura interfere sobremaneira no clima de uma empresa. (LUZ, 2003)

Um outro conceito bem amplo é apresentado por Teixeira (2002) ${ }^{11}$, apud Mol, et a, ( 2010, p. 20)

\begin{abstract}
Clima organizacional é pode ser entendido como a expressão dos sentimentos dos empregados diante dos valores, das políticas, das práticas de gestão de recursos humanos, da forma de relacionamento com os colegas, da postura da empresa ao estabelecer metas e retribuir o alcance delas, a lém da situação econômica. O clima organizacional é formado pela identificação das pessoas com a empresa, principalmente em relação aos desafios, cultura vencedora, reconhecimento, equidade, liderança, oportunidade de carreira, progra ma de treinamento, a mbiente de aprendizagem e a mbiente a colhedor.
\end{abstract}

Neste conceito o autor demonstra a complexidade que envolve a temática clima organizacional quando expõe, por exemplo, diversas áreas relacionadas a gestão de pessoas como treinamento e desenvolvimento, liderança, recrutamento e seleção, gestão do desempenho e remuneração.

Ferreira (2014, p.47), faz menção do conceito de clima usado por Luz (1995) que define o clima como: "estado de espírito ou ânimo das pessoas, que predomina em um ambiente organizacional em determinado período". Segundo a autora o clima é afetado por variáveis internas e externas a organização, mas o cenário interno é o que mais afeta o clima.

Observa-se que mesmo com o passar do tempo o conceito de clima está baseado na percepção e satisfação passando pela interferência no comportamento dos sujeitos e está ligado ao ambiente organizacional (LI; BHUTTO; NASIRI; SHAIKH; SAMO, 2018).

\title{
2.2.1. Clima organizacional no setor público
}

As pesquisas de clima organizacional são mais comuns no setor privado e foi nesse contexto que muitas delas foram desenvolvidas. A atual administração pública passa por um momento oportuno para pesquisas dessa natureza uma vez que a mesma tem passado por um amplo processo de mudança. "Esse processo se visualiza nas sucessivas reformas e definições de estruturas, processos e instrumentos de gestão visando combater a gestão burocráticas tradicional do setor público, tida como ineficaz e ineficiente" (MOL et al, 2010, p.27).

Michel Crozier (1991) ${ }^{12}$ citado por Mol et al (2010) dizia que o estado moderno deveria ser modesto, ou seja, dado que não seria possível fazer tudo era necessário fazer escolhas estratégicas.

O processo de transformação no qual se passa gestão pública é muito associada à visão burocrática e ao management clássico, "que tem sido objeto de fortes críticas em razão das

11 TEIXEIRA, J. E. Clima organizacional: empregados satisfeitos fazem bem aos negócios. In: BOOG, G.; BOOG, M. (Coords.). Manualde gestão de pessoas e equipes. São Paulo: Gente, 2002.v.2.

12 CROZIER, Michel. Etat modeste Etat moderne: stratégies pour um autre changement. Paris: Seuil, 1991.

\section{Campo Jurídico|Barreiras (BA)| v.9 |e663| p.01-30 |Janeiro-Junho|2021}


suas práticas utilitaristas mais voltadas para os meios que para os fins". Trosa (2006) ${ }^{13}$ citado por Mol et al (2010) cita algumas práticas que também são observadas no Brasil:

Ênfase ao funcionamento interno da administração; destaque para os instrumentos de racionalização interna referente a gestão de processos; priorização da eficiência (meios/resultados) em detrimento dos resultados da ação, ou seja, da eficácia (alcance dos objetivos/avaliação); falta de ligação entre aspectos como a modernização interna da administração, o êxito das políticas públicas e a relação entre administração e cidadãos (MOL et al, 2010).

Diversas foram as tentativas de fazer reformas no campo da administração pública. A partir de 1980 passaram a surgir modelos que em geral se contrapõem ao management clássico. Os autores passaram a denominar esse modelo como new public management (NPM), outros simplesmente passaram a chamar de nova gestão pública. O NPM "expressa um conjunto de reformas inspiradas nas formas de gestão do setor privado, iniciadas nos países anglo-saxões, tendo sido em seguida copiadas ou adaptadas e transferidas aos países mais diversos visand o modernizar e inovar o setor público" (MOL et al, 2010).

Esse modelo de gestão conhecido também como "management pós burocrático" pode ser descrito como "estratégico, flexível e promotor da valorização dos funcionários quanto dos cidadãos-usuários dos serviços públicos". Trosa (2006) citado por Mol et al (2010) destaca os seguintes pontos: "a especificação de responsabilidades e papéis; fazer escolhas e programar respeitand o os prazos; estabilidade da gestão; obrigações e liberdades”.

Nesse modelo de gestão existe o pressuposto de valorização do funcionário e sua responsabilização para tanto o ambiente organizacional deve permitir tanto a responsabilização quanto e a autonomia que também lhe é atribuído. "A questão que se coloca é como transformar um ambiente pautado no funcionamento de uma administração de cunho burocrático para uma administração flexível, transparente e participativa". Esse desafio se torna ainda maior quando se nota que no serviço público as pessoas muitas das vezes estão desmotivadas, faltando muito ao trabalho, desenvolvendo doenças ocupacionais, e insatisfeitas com trabalho realizado. Junta-se a esse cenário a falta de políticas que visem o desenvolvimento de ações de promoção à saúde do trabalhador. A partir desse cenário, é importante mapear os elementos que interferem no clima organizacional com vistas a reestruturar as instituições públicas bem como trabalhar com a questão da identidade do servid or público (MOL, et al, 2010, p.29).

\subsubsection{Modelos de estudo de clima organizacional}

Ao longo dos anos diversas pesquisas sobre clima organizacional foram feitas e a partir disso foram postulados alguns modelos de estudo. Segundo Mol et al. (2010) a literatura apresenta diversas medidas e unidades de análise, sendo que elas podem ser objetivas e subjetivas.

As medidas objetivas revelam dados sobre as organizações, tais como suas propriedades e características mensuráveis. Os indivíduos informam, mas não interferem na realidade. As medidas subjetivas apreendem as propriedades organizacionais e/ou individuais por meio de instrumentos que se utilizam da percepção dos participantes ou membros. (MOL et al, 2010, p. 21).

É relevante ressaltar que o clima organizacional considerado como variável dependente é influenciado pela "estrutura gerencial, tecnologia usada pela organização e estilo gerencial". Na prática isso quer dizer que o clima está propenso ao tipo da estrutura organizacional (base piramidal ou horizontal), a estrutura (centralizada ou descentralizada) e

13 TROSA, Sylvie. Vers um management post burocratique, la reforme de l'Etat, une reforme de la société. Paris: L'Harmattan, 2006.

Campo Jurídico|Barreiras (BA)| v.9 |e663| p.01-30 |Janeiro-Junho|2021 
também ao estilo gerencial (autoritário ou participativo). O clima organizacional pode ser visto também como variável independente que influencia por exemplo a satisfação no trabalho (MOL et al, 2010, p. 22).

A seguir, apresentam-se os principais estudos feitos sobre a referida temática. $\mathrm{O}$ Quadro 1 mostra o compilado feito por Mol, et al. (2010):

QUADRO 1 - Modelos de clima organizacional segundo diversos autores

\begin{tabular}{|l|l|}
\hline Modelos/autores & Dimensões \\
\hline $\begin{array}{l}\text { Litwin e } \\
\text { Stringer (1968) }\end{array}$ & Estrutura; responsabilidade; riscos; recompensa; conflito; calore apoio; e sentimento. \\
\hline $\begin{array}{l}\text { Campbell et al. } \\
(1970)\end{array}$ & $\begin{array}{l}\text { Autonomia; grau de estrutura; orientação para recompensa; consideração e calor } \\
\text { humano; e apoio. }\end{array}$ \\
\hline $\begin{array}{l}\text { Schneider } \\
(1975)\end{array}$ & $\begin{array}{l}\text { Suporte administrativo; estrutura administrativa; preocupação com novos servidores; } \\
\text { independência dos servidores; conflitos internos; e satisfação geral. }\end{array}$ \\
\hline Sbragia (1983) & $\begin{array}{l}\text { Estado de tensão; conformidade exigida; ênfa se na participação; proximidade da } \\
\text { supervisão; consideração humana; adequação da estrutura; autonomia presente; } \\
\text { recompensas proporcionais; prestígio obtido; cooperação existente; padrões } \\
\text { enfatizados; atitudes diante dos conflitos; sentimento de identidade; tolerância } \\
\text { existente; clareza percebida; justiça predominante; condições de progresso; apoio } \\
\text { logístico proporcionado; reconhecimento proporcionado; e forma de controle; }\end{array}$ \\
\hline $\begin{array}{l}\text { Kolb al. } \\
\text { (1986) }\end{array}$ & $\begin{array}{l}\text { Conformismo; responsabilidade; padrões; recompensa; cla reza organizacional; ca lor e } \\
\text { apoio; e liderança; }\end{array}$ \\
\hline $\begin{array}{l}\text { Peltz } \\
\text { Andrews, apud } \\
\text { Oliveira (1990) }\end{array}$ & $\begin{array}{l}\text { Liberdade; comunicação; diversidade; dedicação; motivação; satisfação; similaridade; e } \\
\text { criatividade; }\end{array}$ \\
\hline Colossi (1991) & $\begin{array}{l}\text { Filosofia e ambiente geral da empresa; condições físicas de trabalho; sistema de } \\
\text { avaliação e controle; treinamento e desenvolvimento profissional; progresso funcional; } \\
\text { comportamento das chefias; satisfação pessoal; sistema de assistência e benefício; } \\
\text { lazer; e relacionamento sindical; }\end{array}$ \\
\hline Rizzatti (19950 & $\begin{array}{l}\text { Imagem e a valiação; desenvolvimento de recursos humanos; ben efícios e incentivos; } \\
\text { organização e condições de trabalho; relacionamento interpessoal; satisfação pessoal; } \\
\text { sucessão político-administrativa; e comportamento das chefias; }\end{array}$ \\
\hline
\end{tabular}

Fonte: Rizzatti (2006) apud Torres e Oliveira (2007).

Como se observa os diversos autores tratam de variáveis que são objetivas e também subjetivas. Tendo o clima organizacional grande amplitude em geral ele está relacionado em outros tipos de investigação, como satisfação no trabalho e motivação. $O$ clima tem interferência no comportamento dos funcionários e pode alterar a produtividade, a motivação e a satisfação. Para fazer a análise dessas diversas dimensões várias pesquisas têm se usado de recursos quantitativos e métodos estatísticos para fazer as comparações e estudo relacionados ao clima (MOL et al, 2010).

Antes de compreender como se dá uma pesquisa de clima organizacional é importante conhecer um processo psicológico que está diretamente ligado ao clima dentro das empresas: a motivação.

\section{Motivação}

O tema motivação é bem recorrente quando se estuda a temática clima organizacional, motivo este que um tópico será dedicado a compreensão desse assunto.

Uma definição clara sobre clima pode ser encontrada no livro de Vergara (2012, p.42) como: "motivação pode ser definida como uma força, uma energia que nos impulsiona na direção de alguma coisa, além disso, ela é absolutamente intrínseca, isto é, está dentro de cada

\section{Campo Jurídico|Barreiras (BA)| v.9 |e663| p.01-30 |Janeiro-Junho|2021}


um e nasce de suas necessidades interiores". Partindo dessa definição entendemos que "ninguém motiva ninguém" o que podemos fazer é tentar estimular as pessoas para que elas encontrem a motivação. Pode parecer simples, mas isso é bem mais complexo do que se imagina uma vez que isso leva em consideração a individualidade dos sujeitos e momento pelo qual estão passando (VERGARA, 2012; FERREIRA, 2014).

França (2006, p.24) considera ainda como características da motivação: "processo interno ou subjetivo; processo individual compartilhado ou não; motivos para ação; e focar o comportamento em determinada direção". Tais características apenas reforçam o caráter subjetivo e individual já mencionado por Vergara (2012) e Ferreira (2014).

É consenso na literatura que não é possível motivar ninguém, o que se pode fazer é estimular a pessoa para que ela se motive, Handy citado por Bergamini faz colocação onde fica evidente o desafio da motivação, especialmente no ambiente organizacional:

\begin{abstract}
Se pudéssemos compreender, e então prever os modos como os indivíduos são motivados, poderíamos influenciá-los, alterando os componentes desse processo de motivação. Talcompreensão poderia certamente levarà obtenção de gra nde poder, uma vez que permitiria o controle do comportamento sem armadilhas visíveis e impopulares do controle. Os primeiros trabalhos acerca da motivação demonstraram preocupação em encontrar os modos pelos quais o indivíduo poderia ser motiva do e aplicar mais do seu esforço e talento a serviço do seu empregador. É mera questão de justiça acrescentarmos que muitos desses teóricos também se preocupavam em encontrar uma resposta que fosse coerente com a dignidade e independência essenciais do indivíduo. Talvez devêssemos sentir alívio quanto ao fato de que não foi encontrada qualquer fórmula garantida de MOTIVAÇÃO (HANDY, 1978 apud BERGAMINI, 1990, p. 39 ${ }^{14}$.
\end{abstract}

Bergamini (1990) vem reforçar a ideia do processo motivacional como sendo algo que vem do interior de cada pessoa:

Há grande diferença entre o movimento causado pelas reações aos agentes condicionantes extrínsecos ao indivíduo e a motivação que nasce das necessidades intrínsecas e que encontram, sua fonte de energia nas necessidades e emoções - sob esse aspecto só se pode falar em verdade motivação quando ela for compreendida como algo interior de cada pessoa.(BERGAMINI, 1990, p. 39).

Avançando um pouco mais no entendimento do conceito de motivação, Ferreira (2014) e França (2006) traz para discussão o conceito de ciclo motivacional. A Figura 1 ilustra o ciclo. "As pessoas têm necessidades que, quando se manifestam, geram tensões que são direcionadas para um estímulo ou ação que atenda a necessidade latente. Essas necessidades são individuais e influenciadas pela cultura" (FRANÇA, 2006; HASHEMI; SADEQI, 2016).

\footnotetext{
${ }^{14}$ HANDY, C. B. Como compreenderas organizações? Rio de Janeiro: Zahar, 1978.p.27
} 


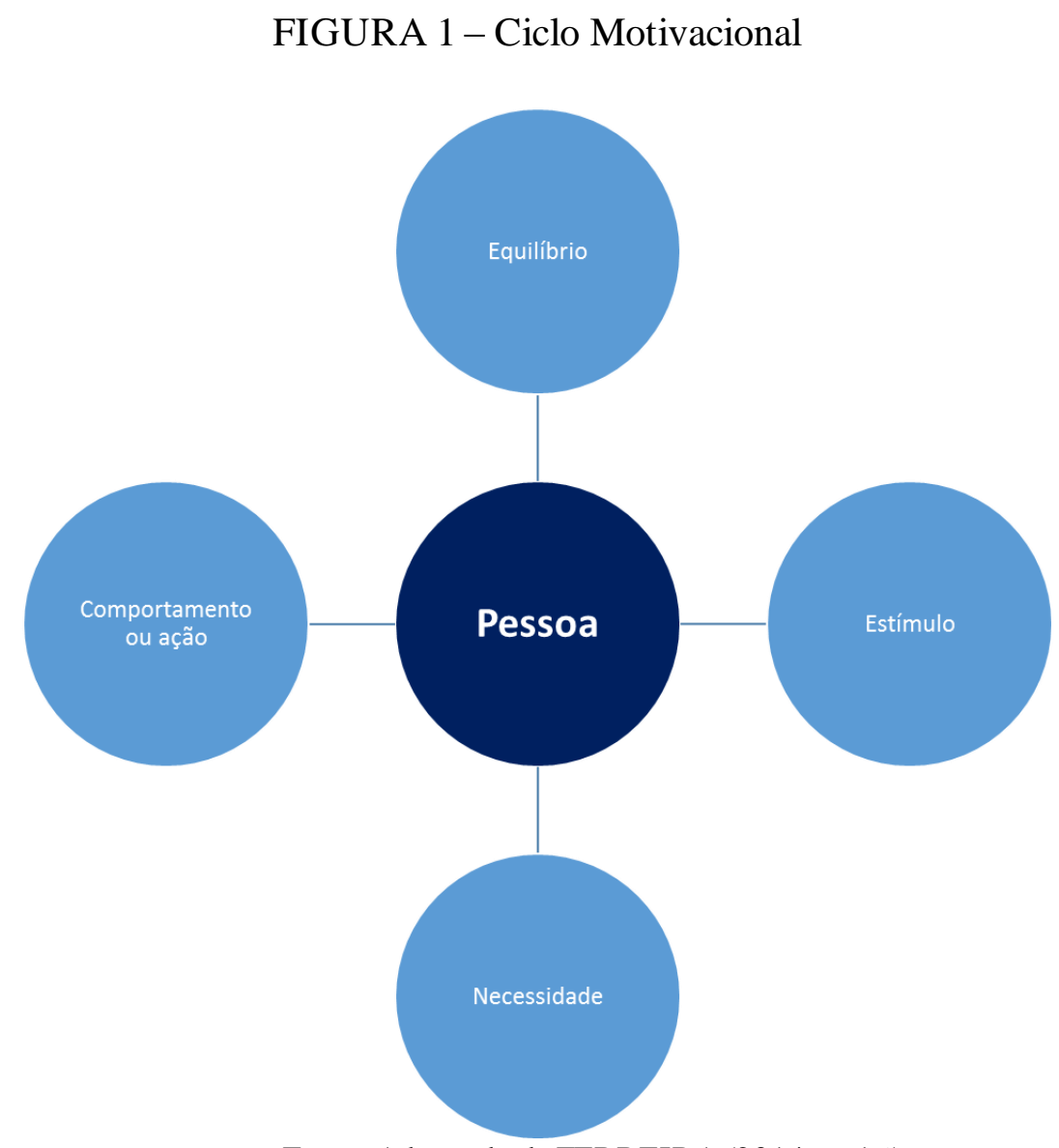

Fonte: Adaptado de FERREIRA (2014, p. 16).

Quando se fala em necessidade, encontramos na literatura várias teorias que suportam as explicações para as necessidades humanas. $\mathrm{O}$ foco será as necessidades relacionadas ao mundo do trabalho. França (2006, p.24) diz que "a motivação para trabalhar é o resultado de uma ou mais necessidades que serão atendidas mediante um determinado comportamento ou conjunto de ações".

O Quadro 2 consolida as principais teorias relacionadas a necessidades na contemporaneidade conforme França (2006):

QUADRO 2 - Teorias Contemporâneas de Necessidades

\begin{tabular}{|c|c|c|}
\hline Nome da teoria & Autor & Descrição \\
\hline $\begin{array}{l}\text { Teoria das } \\
\text { Necessidades } \\
\text { Básicas }\end{array}$ & McChelland & $\begin{array}{l}\text { O ser humano apresenta necessidades básicas que se manifestam com } \\
\text { determinada intensidade em momentos específicos. Essas necessidades são } \\
\text { de: realização, podere associação. }\end{array}$ \\
\hline $\begin{array}{l}\text { Hierarquia das } \\
\text { Necessidades }\end{array}$ & $\begin{array}{l}\text { Abram } \\
\text { Maslow }\end{array}$ & $\begin{array}{l}\text { Essa teoria leva em consideração que as motivações humanas decorrem da } \\
\text { satisfação de necessidades específica que são classifica das em cinco níveis, } \\
\text { a saber: } \\
\text { - Básicas: a limentação, repouso e continuidade da espécie e se } \\
\text { expressam por meio da fome, sono e sexo; } \\
\text { - Segurança: proteção física e mental, e ausência de ameaça à } \\
\text { integridade. São expressas mediante habitação, a segurança e a } \\
\text { proteção pessoal; } \\
\text { Associação: o conjunto de relações nos mais diversos grupos aos quais } \\
\text { pertencemos. É expresso por meio dos amigos, parceiros, semelhança } \\
\text { ou complementaridade de interesses. } \\
\text { - Reconhecimento: procura de prestígio e valorização pessoal diante de }\end{array}$ \\
\hline
\end{tabular}




\begin{tabular}{|c|c|c|}
\hline & & $\begin{array}{l}\text { outras pessoas, grupos ou culturas. Refletem-se na busca de poder, } \\
\text { posse, qualificação pessoale profissional. } \\
\text { - Autorrealização: as ações que nos realizam de forma pessoal e única. } \\
\text { Atingem o nosso conjunto intrínseco de vontades e/ou crenças. Podem } \\
\text { ser percebidas na dedicação incondicional e na motivação consistente } \\
\text { com hábitose sentimento de prazer. } \\
\text { Essas necessidades obedecem sendo o autor uma hierarquia sendo que } \\
\text { quando uma está razoavelmente satisfeita as do próximo nível se tornam } \\
\text { mais potentes como fontes motivadoras. }\end{array}$ \\
\hline $\begin{array}{l}\text { Teoria dos Dois } \\
\text { fatores }\end{array}$ & Herzberg & $\begin{array}{l}\text { O autor concluiu que as pessoas geralmente se associavam a diferentes tipos } \\
\text { de condições para os bons (positivos) ou maus (negativos) sentimentos, ou } \\
\text { seja, que existem dois fatores diferentes influenciando a motivação. Fatores } \\
\text { ligados às insatisfações, os fatores de higiene ou manutenção que são } \\
\text { necessários para manter um nível razoável de motivação entre os } \\
\text { empregados. Outros fatores, os de motivação funcionam para o aumento da } \\
\text { motivação no trabalho. }\end{array}$ \\
\hline
\end{tabular}

Fonte: a daptado de França (2006, p.) 24-26).

Todas essas teorias reforça a complexidade que envolve o tema motivação. Expostas todas essas teorias é importante destacar que o clima organizacional é altamente influenciador da motivação das pessoas tendo em vista que é em variáveis do clima organizacional que se encontra os estímulos externos que desencadeiam sentimentos nos funcionários sendo capaz de alterar seus comportamentos de maneira positiva ou negativa.

\subsubsection{Etapas da pesquisa de clima organizacional}

Esse é o último tópico do referencial teórico, e não menos importante, uma vez que trata das etapas processuais de uma pesquisa de clima organizacional.

Cabe reforçar aqui o objetivo de uma pesquisa de clima organizacional, que segundo Lima e Stano (2004) é:

[...] maximizar, cada vez mais, suas relações com os colaboradores oferecendo condições de trabalho adequadas, proporcionando oportunidades de desenvolvimento e estabelecendo um ótimo ambiente de trabalho, o que proporcionará o alcance e a superação dos objetivos definidos pela Diretoria. (LIMA; STANO, 2004.p. 5).

Ainda segundo esses dois autores a pesquisa de clima organizacional traz diversas contribuições, cabendo destacar:

- $\quad$ Conhecer os anseios das pessoas da organização;

- Buscar o alinhamento da cultura com as ações efetivas da empresa;

- Identificar pontos fortes e pontos fracos do relacionamento empresa $\mathrm{x}$ empregado;

- Diagnosticar as origens dos possíveis problemas de gestão de pessoas (ex. turnover, absenteísmo, acidentes no trabalho etc.)

- Identificar as práticas e funções de RH que necessitam de melhorias;

- Melhoria das condições físicas do ambiente de trabalho;

- $\quad$ Promover o crescimento e desenvolvimento dos colaboradores;

- Integrar os diversos processos e áreas funcionais;

- Otimizar a comunicação;

- Identificar os perfis de gerência existentes;

- Identificar necessidades de treinamento, desenvolvimento pessoal/gerencial e de educação empresarial; 
- Enfocar o cliente interno e externo;

- Otimizar as ações gerenciais, tornando-as mais consistentes;

- Organizar, flexibilizar e agilizar as atividades da organização, dentre outras ${ }^{15}$. (LIMA; STANO, 2004)

Segundo Luz (2003, p. 49) uma pesquisa de clima organizacional passa por onze etapas a saber:

$\left.1^{\circ}\right)$ Obtenção da aprovação e do apoio da direção;

$2^{\circ}$ ) Planejamento da Pesquisa - definição do objetivo, público, quem vai conduzir, técnica a ser usada, coleta, periodicidade ou momento de aplicação, tabulação, divulgação, preparação das chefias, abrangência da pesquisa etc;

$3^{\circ}$ ) Definição das variáveis (assuntos) a serem pesquisadas;

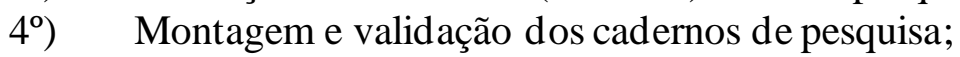

$\left.5^{\circ}\right)$ Parametrização para tabulação as opções de resposta;

$6^{\circ}$ ) Divulgação da pesquisa;

$7^{\circ}$ ) Aplicação e coleta da pesquisa;

$8^{\circ}$ ) Tabulação da pesquisa;

$9^{\circ}$ ) Emissão de relatórios;

$10^{\circ}$ ) Divulgação dos resultados da pesquisa;

$11^{\circ}$ ) Definição de Plano de ação.

Cabe ressaltar que esse autor é reconhecido na literatura sendo que diversos trabalhos menção a suas obras. Dentre os trabalhos mais atuais podemos citar Ferreira (2014) que enumera as mesmas etapas de Luz (2003).

Por fim é importante destacar que a temática de qualidade de vida no trabalho está muito evidente atualmente porque o mesmo tem grande influência no clima organizacional (FERREIRA, 2014).

Encerra-se aqui o referencial teórico, cujo propósito foi apresentar os principais conceitos teóricos referentes ao trabalho proposto com vistas a permitir um melhor entendimento dos capítulos que se seguem.

\section{METODOLOGIA DA PESQUISA}

Neste capítulo são apresentados os procedimentos que aconteceram para que fosse possível a realização da pesquisa. Como trata-se de um trabalho acadêmico foi seguida as ações necessárias e já padronizadas para que o resultado tivesse validade acadêmica.

\subsection{Caracterização da pesquisa}

Tendo em vista os objetivos deste trabalho, foi feita uma pesquisa descritiva. $\mathrm{O}$ meio no qual busca-se o atingimento dos resultados foi a pesquisa bibliográfica e o estudo de caso. As análises foram feitas a partir de uma abordagem quantitativa tendo em vista os meios usados para obtenção dos resultados.

O estudo de caso é uma forma empírica que analisa um fenômeno atual dentro de um contexto da realidade, quando as fronteiras entre o fenômeno e o contexto não são claramente definidas e no qual são utilizadas várias fontes de evidência (YIN, 2001).

\footnotetext{
${ }^{15}$ Retirado na íntegra do livro de LIMA e STANO, 2004.p. 5
} 
Para Ventura (2007, p.385) "como qualquer pesquisa, o estudo de caso é geralmente organizado em torno de um pequeno número de questões que se referem ao como e ao porquê da investigação".

Foi escolhido o estudo de caso para analisar o clima organizacional da instituição tendo em vista que o caráter voluntário de participação na pesquisa, além disso, o arcabouço do pesquisador no que diz respeito ao tipo de análise a ser feita.

\subsection{Instrumentos de coleta de dados}

Para realização da pesquisa de clima foi montado um questionário baseado no trabalho feito por Mol et al. (2010). O formulário original usado na pesquisa realizada na Secretaria de Administração e Recursos Humanos do Rio Grande do Norte não foi obtido mesmo depois de tentativas de contato com os autores. Foi feito contato na secretaria de curso onde os pesquisadores são lotados e também por e-mail, mas nenhum retorno foi obtido. Além disso foi feita busca na internet com objetivo de conseguir o questionário usado, mas este também não foi encontrado.

Dado que o trabalho realizado pelos autores é aplicado na administração pública o mesmo não poderia ser ignorado, sendo assim procedeu com a elaboração das questões basead as nos resultados apresentados pelos autores.

O formulário foi construído então considerando as questões levantadas pelos autores e também foram inseridas 3 questões e não incorporadas na versão final do instrumento 2 perguntas, sendo assim o questionário foi adaptado do modelo proposto por Mol et al. (2010).

Por fim o questionário ficou com a seguinte estrutura:

QUADRO 3 - Estrutura por dimensão do instrumento de coleta de dados

\begin{tabular}{|l|l|}
\hline Dimensão & $\mathrm{N}^{\circ}$ de questões \\
\hline Perfil dos servidores & 7 \\
\hline Estrutura e ambiente físico & 3 \\
\hline Cooperação e reciprocidade no a mbiente de trabalho & 5 \\
\hline Participação nas decisões & 4 \\
\hline Reconhecimento de mérito & 3 \\
\hline Identificação com a instituição & 5 \\
\hline Controles & 3 \\
\hline Autonomia funcional & 4 \\
\hline Conflitos & 3 \\
\hline Remuneração e oportunidade & 3 \\
\hline Perspectiva na Instituição & 2 \\
\hline
\end{tabular}

Fonte: elaborado pelos autores.

Ressalta-se que o formulário foi construído pelos autores considerando outros modelos de pesquisa de clima organizacional, especialmente os modelos aplicados no setor privado. A proposta dos autores é que o instrumento fosse mais aderente a realidade do setor público.

O estudo conduzido pelos autores foi realizado na Secretaria de Administração e Recursos Humanos do Rio Grande do Norte entre outubro e novembro de 2009, sendo que participaram da pesquisa 242 servidores públicos. Foram feitas análises estatísticas que visaram verificar a consistência do banco de dados (MOL et al., 2010).

Além do questionário foi usada também a observação direta participante como forma de coleta de dados. Essa observação foi feita pelo autor que atuava em um dos setores que a pesquisa foi aplicada bem como já tinha atuado e tinha relação indireta com o outro setor pesquisado. 


\subsection{População e amostra}

A população do estudo estava distribuída conforme segue no Quadro 4. O universo total era de 8.761 servidores ativos tomando como base o mês de dezembro de 2014.

QUADRO 4 - Quantidade de servid ores por órgão e situação funcio
\begin{tabular}{|l|c|}
\hline \multicolumn{1}{|c|}{ SECRETARIA DE ESTADO DE PLANEJAMENTO E GESTAO } \\
\hline Tipo de Vínculo - Situação Funcional & Quantidade de servidores \\
\hline CONTRATO LEI 18.185/2009 & 67 \\
\hline DETERM. JUDICIAL - INDENIZACAO & 1 \\
\hline EFETIVO & 506 \\
\hline EFETIVO (APOS LEI 64/2002) & 584 \\
\hline FUNCAO PUBLICA & 2 \\
\hline MEMBRO ACADEPOL/ORG.DEL.COLET. & 2 \\
\hline RECRUTAMENTO AMPLO & 277 \\
\hline Total & 1439 \\
\hline
\end{tabular}

\begin{tabular}{|l|c|}
\hline \multicolumn{2}{|c|}{ SECRETARIA DE ESTADO DE SAÚDE } \\
\hline Tipo de Vínculo - Situação Funcional & Quantidade de servidores \\
\hline CONTRATO LEI 18.185/2009 & 370 \\
\hline DETERM. JUDICIAL - INDENIZACAO & 6 \\
\hline EFETIVO & 5857 \\
\hline EFETIVO (APOS LEI 64/2002) & 669 \\
\hline FUNCAO PUBLICA & 11 \\
\hline GRATIFICADOS & 64 \\
\hline MEMBRO ACADEPOL/ORG.DEL.COLET. & 2 \\
\hline RECRUTAMENTO AMPLO & 341 \\
\hline DECISAO ADI N.4876 - STF & 2 \\
\hline Total & 7322 \\
\hline
\end{tabular}

Fonte: Elaborado pelos autores com dados da SEPLAG (2015).

O questionário foi enviado por e-mail no período de 19 janeiro à 23 de janeiro 2016 aos servidores. Foi indicado que o prazo para resposta seria até o dia 06 de fevereiro. Após esse período o mesmo foi fechado para novas respostas.

A pesquisa não foi realizada de forma institucional, ou seja, não teve apoio formal da liderança. Considerando essa restrição o pesquisad or encaminhou a pesquisa somente para as pessoas com quem tinha certa relação de amizade ou contato profissional. Essa situação se repetiu nas duas instituições pesquisadas. Não foi feito levantamento de quantos questionários foram enviados para cada setor interno das secretarias uma vez que em momento não seria questionado ao participante seu setor de trabalho. Esse procedimento foi adotado com o objetivo de dar mais tranquilidade na participação da pesquisa.

O Quadro 5 mostra a distribuição de questionários enviados e respondidos por órgão. Como se observa, a amostra de conveniência usada pelo pesquisador foi pequena quando há comparação com todos os servidores da secretaria. O percentual de participação, ou seja, aqueles que de fato responderam à pesquisa foi significativo, principalmente na SEPLAG cuja adesão foi $76,40 \%$. 
QUADRO 5 - Total de servidores, público selecionado e participantes da pesquisa de clima organizacional

\begin{tabular}{|l|r|}
\hline \multicolumn{2}{|c|}{ SECRETARIA DE ESTADO DE SAÚDE } \\
\hline Número total de Servidores & 7.322 \\
\hline Questionário enviados & 79 \\
\hline Questionário recebidos & 31 \\
\hline$\%$ de público selecionado & $1,08 \%$ \\
\hline$\%$ de público participantes em relação aos selecionados & $39,24 \%$ \\
\hline
\end{tabular}

\begin{tabular}{|l|r|}
\hline \multicolumn{2}{|c|}{ SECRETARIA DE ESTADO DE PLANEJAMENTO E GESTAO } \\
\hline Número total de Servidores & 1.439 \\
\hline Questionário enviados & 89 \\
\hline Questionário recebidos & 68 \\
\hline$\%$ de público selecionado & $76,18 \%$ \\
\hline$\%$ de público participantes em relação aos selecionados & $70 \%$ \\
\hline
\end{tabular}

Fonte: elaborado pelos autores.

O questionário foi feito elaborado no Google Docs, na plataforma Web e disponibilizado aos servidores através do link: http://migre.me/oGaYk.

\subsection{Tratamento dos dados}

Os dados coletados foram analisados estatisticamente no programa PASW Statistics 18 e também no Microsoft Excel, versão 2013.

As respostas obtidas não foram submetidas a nenhum teste estatístico para verificar consistência nem confiabilidade. As informações foram tratadas no programa mencionado para que fosse possível obter os percentuais de percepção dos servidores das dimensões realizadas. Entende-se as limitações do método, no entanto procura-se atender aos objetivos do trabalho.

\section{ANÁLISE DOS DADOS}

Este capítulo irá trazer para a discussão os principais resultados agrupados por dimensão conforme descrito no capítulo de metodologia. Para que seja possível entender melhor os locais selecionados, será feita uma apresentação dos cenários de pesquisa para contextualizar o leitor dos achados que serão apresentados e em seguida discutidos.

\subsection{Apresentação do cenário de pesquisa}

Conforme já explicitado o pesquisado optou por realizar a pesquisa em duas secretarias de Estado ligadas ao Governo de Minas Gerais. Ambas ficam localizadas na Cidade Administrativa no bairro Serra Verde ao longo da MG-10. A foto na Figura 2 mostra uma visão parcial, de onde estão localizadas as secretarias (Prédio Minas e Gerais) alvo da pesquisa de clima, na Cidade Administrativa: 
FIGURA 2 - Foto parcial da Cidade Administrativa Presidente Tancredo Neves.

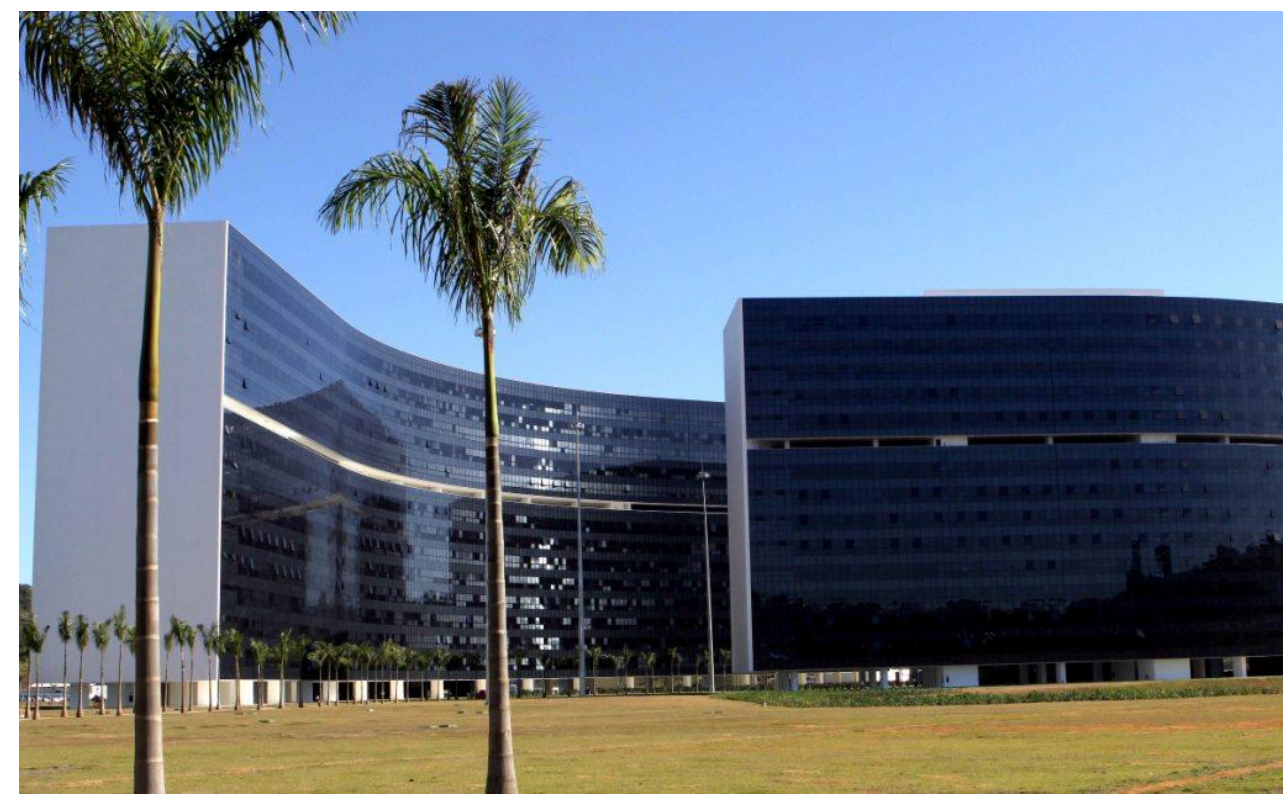

Fonte: Retirada da base da SEPLAG (2007).

\subsubsection{Secretaria de Estado de Planejamento e Gestão}

As informações a seguir foram retiradas na íntegra do site institucional da SEPLAG.

A Secretaria de Estado de Planejamento e Gestão foi criada pela Lei Delegada $\mathrm{n}^{\circ} 112$, de 25 de janeiro de 2007, tendo como finalidade "coordenar a formulação, a execução e a avaliação de políticas públicas, visando ao desenvolvimento econômico, social e institucional do Estado; propor e executar políticas públicas nas áreas de recursos humanos, orçamento, recursos logísticos e tecnológicos, modernização administrativa, perícia médica e saúde ocupacional".

Em 2011, a Lei Delegada n ${ }^{\circ} 179$ de 01 de janeiro de 2011 dispõe sobre a organização básica e a estrutura vigente da Administração Pública do Poder Executivo do Estado de Minas Gerais, cujo art. $2^{\circ}$ define a estrutura orgânica da Administração Pública do Poder Executivo do Estado e no inciso XV do art. $5^{\circ}$, a estrutura da Secretaria de Estado de Planejamento e Gestão - SEPLAG:

XV - Secretaria de Estado de Planejamento e Gestão:

a) Subsecretaria de Gestão de Pessoas;

b) Subsecretaria de Planejamento, Orçamento e Qualidade do Gasto; e

c) Subsecretaria de Gestão da Estratégia Governamental

A Lei Delegada $n^{\circ} 180$ de 20 de janeiro de 2011, por sua vez, ao dispor sobre a estrutura orgânica da Administração Pública do Poder Executivo do Estado de Minas Gerais, define em seu art. 211 a finalidade e as competências da SEPLAG:

Art. 211 A Secretaria de Estado de Planejamento e Gestão - SEPLAG -, a que se refere o inciso XV do art. $5^{\circ}$ da Lei Delegada $n^{\circ} 179$, de 2011, tem por finalidade coordenar a formulação, a execução e a avaliação de políticas públicas visando ao desenvolvimento econômico, social e institucional do Estado; propor e executar políticas públicas de recursos humanos, orçamento, recursos logísticos e tecnologia da informação e comunicação, modernização administrativa e saúde ocupacional; bem como exercer a coordenação geral das ações de governo e a gestão da estratégia governamental, competindo- lhe: 
I - formular, propor, planejar e coordenar a ação governamental, mediante a elaboração, o acompanhamento e o controle de planos, programas e projetos globais e regionais, de duração anual e plurianual, e a proposição de diretrizes para o desenvolvimento econômico e social do Estado, garantindo a execução do planejamento estratégico do Governo;

II - assegurar a efetividade, conceber e articular a execução, acompanhar as metas e os resultados e identificar as restrições e as dificuldades das políticas públicas setoriais e multissetoriais destinadas a regiões ou segmentos populacionais específicos;

III - integrar esforços nas esferas de governo federal, estadual e municipal, assim como entre os Poderes do Estado, coordenando e gerenciando o processo de planejamento global das atividades do Estado, visando ao melhor atendimento às demandas da sociedade e ao desenvolvimento do Estado;

IV - propor e difundir modelos, estabelecer normas, coordenar, acompanhar e supervisionar ações voltadas para a modernização da Administração Pública Estadual e gerir informações institucionais;

$\mathrm{V}$ - propor, implementar e difundir políticas de modernização de tecnologia da informação e comunicação do Estado, bem como promover a orientação normativa, a coordenação logística, a execução e o controle das atividades relativas a patrimônio, compras e transporte oficial;

VI - coordenar, compatibilizar e avaliar a alocação de recursos orçamentários e financeiros, tendo em vista as necessidades das unidades da Administração Pública, para o cumprimento dos objetivos e metas governamentais, bem como acompanhar sua execução;

VII - estabelecer normas, ações e políticas de recursos humanos direcionadas ao recrutamento e seleção, à avaliação, ao desenvolvimento, à qualificação e à valorização do servidor público, assim como orientar, coordenar, acompanhar e supervisionar sua implementação;

VIII - promover a orientação normativa, a supervisão técnica, a fiscalização, a execução e o controle das atividades de perícia médica, bem como gerir a política de saúde ocupacional no âmbito do Poder Executivo;

IX - promover a orientação normativa, a supervisão técnica, a fiscalização, a execução e o controle das atividades de administração e pagamento de pessoal da Administração Pública do Poder Executivo;

$X$ - estabelecer políticas, diretrizes e normas para a disponibilização de informações a cidadãos, empresas, governo e servidores e para a gestão da informação e dos recursos de tecnologia da informação e comunicação;

XI - estabelecer políticas, diretrizes e metodologias para integração e racionalização dos processos organizacionais do Estado, buscando simplificar a relação do Estado com cidadãos, empresas, governo e servid ores;

XII - coordenar e supervisionar as atividades das Unidades de Atendimento Integrado - UAIs; XIII - promover a orientação normativa e a supervisão técnica relativas às parcerias entre o Poder Executivo e as organizações da sociedade civil; e

XIV- exercer atividad es correlatas.

Ainda no art. 212, a Lei Delegada nº 180 de 2011 define a seguinte estrutura orgânica básica da Secretaria de Estado de Planejamento e Gestão:

I - Gabinete;

II - Auditoria Setorial;

III - Assessoria Jurídico-Administrativa;

Campo Jurídico|Barreiras (BA)| v.9 |e663| p.01-30 |Janeiro-Junho|2021 
IV - Assessoria de Gestão Estratégica e Inovação;

V - Assessoria de Apoio Administrativo;

VI - Assessoria de Comunicação Social;

VII - Subsecretaria de Planejamento, Orçamento e Qualidade do Gasto:

a) Superintendência Central de Planejamento e Programação Orçamentária;

b) Superintendência Central de Coordenação Geral; e

c) Superintendência Central de Recursos Logísticos e Patrimônio;

VIII - Subsecretaria de Gestão da Estratégia Governamental:

a) Núcleo Central de Gestão Estratégica de Projetos e do Desempenho Institucional;

b) Núcleo Central de Inovação e Modernização Institucional; e

c) Núcleo Central de Parcerias com organizações da sociedade civil de interesse público OSCIPs;

IX - Subsecretaria de Gestão de Pessoas:

a) Superintendência Central de Administração de Pessoal;

b) Superintendência Central de Perícia Médica e Saúde Ocupacional;

c) Superintendência Central de Política de Recursos Humanos; e

d) Assessoria de Relações Sindicais;

X - Superintendência Central de Governança Eletrônica;

XI - Superintendência de Planejamento, Gestão e Finanças;

XII - Coordenadoria Especial de Gestão das UAIs; e

XIII - Superintendência de Coordenação Regional.

A SEPLAG tem ainda sua organização regida pelo Decreto $\mathrm{n}^{\circ} 45.794$ de 02 de dezembro de 2011, o qual detalha a finalidade e as competências de cada uma de suas Unidades Administrativas (SEPLAG, 2015)

\subsubsection{Secretaria de Estado de Saúde}

As informações a seguir foram retiradas na íntegra do site institucional da SES.

Segundo o decreto $\mathrm{n}^{\circ} 45.812$, de 14 de dezembro de 20111, art. $2^{\circ}$ a SES tem por finalidade formular, regular e fomentar as políticas de saúde pública no Estado de Minas Gerais, atuando em cooperação com os demais entes federados na prevenção, promoção, preservação e recuperação da saúde da população, competindo-lhe:

I - formular e coordenar a política estadual de saúde e supervisionar sua execução nas instituições que integram sua área de competência;

II - monitorar, coordenar, avaliar e consolidar as informações sobre saúde no Estado;

III - formular planos e programas em sua área de competência, observadas as determinações governamentais, em articulação com a Secretaria de Estado de Planejamento e Gestão;

IV - gerenciar, coordenar, controlar e avaliar as políticas do Sistema Único de Saúde -

SUS - no Estado;

$\mathrm{V}$ - promover e coordenar o processo de regionalização e descentralização dos serviços e ações de saúde;

VI - incentivar e fomentar a universalização da atenção primária à saúde, assegurando o acesso às redes de atenção;

VII - normalizar e implantar as redes de atenção à saúde do SUS no Estado;

VIII - formular, em caráter complementar, as políticas de assistência farmacêutica no

Estado;

IX - formular diretrizes para o planejamento das demandas assistenciais de saúde e o credenciamento de instituições para a prestação de serviços de saúde;

$\mathrm{X}$ - coordenar o monitoramento e a avaliação das formas de financiamento do SUS no Estado;

Campo Jurídico|Barreiras (BA)| v.9 |e663| p.01-30 |Janeiro-Junho|2021 
XI - estabelecer normas, em caráter complementar, para o controle, a avaliação e a auditoria das ações e serviços de saúde no Estado;

XII - coordenar e, em caráter complementar, executar ações e serviços de vigilância sanitária, epidemiológica, ambiental, nutricional e de saúde do trabalhador;

XIII - coparticipar da formulação da política de saneamento básico;

XIV - estimular a pesquisa e a incorporação de inovações científicas e tecnológicas no âmbito do SUS;

$\mathrm{XV}$ - editar normas e estabelecer padrões, em caráter suplementar, de procedimentos de controle de qualidade para produtos e substâncias de consumo humano;

XVI - editar, em caráter complementar, normas e regulamentos destinados à prevenção, promoção, proteção e recuperação da saúde da população no Estado;

XVII - fomentar a gestão participativa do SUS;

XVIII - exercer ativid ades correlatas; e

XIX - exercer o poder de polícia no âmbito da sua competência.

$\mathrm{O}$ art. $3^{\circ}$ estabelece que integram a área de competência da Secretaria de Estado de Saúde:

I - por subordinação administrativa:

a) o Conselho Estadual de Saúde - CES; e

b) a Escola de Saúde Pública do Estado de Minas Gerais - ESP/MG;

II - por vinculação:

a) a Fundação Centro de Hematologia e Hemoterapia do Estado de Minas Gerais -

HEMOMINAS;

b) a Fundação Ezequiel Dias - FUNED; e

c) a Fundação Hospitalar do Estado de Minas Gerais - FHEMIG.

\subsection{Perfil da amostra}

O perfil da amostra tem por objetivo apresentar os principais dados sócio econômicos dos indivíduos que participaram da pesquisa a fim de caracterizá-los.

As mulheres foram maioria na pesquisa, representando $(58,6 \%)$ do público que respondeu a pesquisa conforme Tabela 1:

Tabela 1 - Distribuição por sexo dos participantes

\begin{tabular}{lcc}
\hline Sexo & Frequência & Percentual (\%) \\
\hline Feminino & 58 & 58,6 \\
Masculino & 41 & 41,4 \\
\hline Total & 99 & 100,0 \\
\hline \multicolumn{3}{c}{ Fonte: elaborado pelo autor }
\end{tabular}

A idade e o tempo de trabalho são variáveis importantes, especialmente quando se trata do setor público que o vínculo de trabalho das pessoas faz com que as mesmas trabalhem na instituição por um longo período. A idade prevalente na pesquisa compreende a faixa de 25 até 35 anos representando um percentual de $45,5 \%$. É relativamente significativa $(30,3 \%)$ a participação dos servidores de até 25 anos de idade. Em relação ao tempo de trabalho no serviço público de Minas Gerais, encontramos mais da metade das pessoas com até 5 anos de trabalho $(68,8 \%)$.

Tabela 2 - Faixa etária dos servidores participantes

\begin{tabular}{lll}
\hline Faixa etária & Frequência & Percentual $(\%)$ \\
\hline
\end{tabular}




\begin{tabular}{lcc} 
Até 25 anos & 30 & 30,3 \\
Acima de 25 anos e até 35 anos & 45 & 45,5 \\
Acima de 35 anos e até 45 anos & 17 & 17,2 \\
Acima de 45 anos e até 55 anos & 5 & 5,1 \\
Acima de 55 anos & 2 & 2,0 \\
\hline Total & 99 & 100
\end{tabular}

Tabela 3 - Tempo de trabalho no serviço público de Minas Gerais dos participantes da pesquisa

\begin{tabular}{lccc}
\hline Tempo de trabalho & Frequência & $\begin{array}{c}\text { Percentual } \\
(\%)\end{array}$ & $\begin{array}{c}\text { Percentual } \\
\text { Cumulativo } \\
(\%)\end{array}$ \\
\hline Até 3 anos & 44 & 44,4 & 44,4 \\
de 3 a 5 anos & 24 & 24,2 & 68,7 \\
de 5 a 10 anos & 15 & 15,2 & 83,8 \\
de 10 a 15 anos & 7 & 7,1 & 90,9 \\
de 15 a 20 anos & 5 & 5,1 & 96,0 \\
Acima de 20 anos & 4 & 4,0 & 100,0 \\
\hline Total & 99 & 100 & - \\
\hline
\end{tabular}

Fonte: elaborado pelos autores.

A instrução, ou seja, a formação acadêmica de maior participação na pesquisa foi de pessoas com o ensino superior completo correspondendo a 43,4\% dos respondentes.

Tabela 4 - Distribuição do grau de instrução dos participantes

\begin{tabular}{lcc}
\hline Grau de instrução & Frequência & $\begin{array}{c}\text { Percentual } \\
(\%)\end{array}$ \\
\hline Ensino Médio Completo & 4 & 4,0 \\
Superior completo & 43 & 43,4 \\
Superior Incompleto & 8 & 8,1 \\
Pós graduação & 44 & 44,4 \\
\hline Total & 99 & 100,0 \\
\hline \multicolumn{2}{c}{ Fonte: elaborado pelos autores. }
\end{tabular}

A faixa salarial predominante $(34,3 \%)$ no grupo pesquisado corresponde no intervalo de 5 a 8 salários-mínimos ${ }^{16}$, ou seja, de 3.940 reais até 6.304 . Na faixa salarial mais alta (acima de 11 salários-mínimos) encontra-se apenas 10\% do público participante conforme mostra a tabela a seguir:

Tabela 5 - Distribuição por faixa salarial dos participantes

\begin{tabular}{lcc}
\hline Faixa salarial & Frequência & Percentual $(\%)$ \\
\hline Até 2 salários-mínimos (SM) & 13 & 13,1 \\
Acima de 2 SM e até 5 SM & 31 & 31,3
\end{tabular}

\footnotetext{
16 Valor a tualiza do do sa lário-mínimo $(788,00)$ conforme http://portal.mte.gov.br/sal_min/
} 


\begin{tabular}{lll} 
Acima de 5 SM e até 8 SM & 34 & 34,3 \\
Acima de 8 SM e até 11 SM & 11 & 11,1 \\
Acima de 11 SM & 10 & 10,1 \\
\hline Total & 99 & 100 \\
\hline
\end{tabular}

Fonte: elaborado pelos autores.

Por último, na categoria perfil da amostra, temos a distribuição dos vínculos de trabalho dos servidores pesquisados. A maior parte dos entrevistados $(62,6 \%)$ faz parte do quadro efetivo do Estado e com isso goza dos direitos dos servidores públicos tais como a estabilidade após estágio probatório conforme Constituição Federal de 1988 em seu Art. 41. Por outro lado, temos $16,2 \%$ dos entrevistados que são terceirizados e normalmente não gozam dos mesmos direitos que os servidores efetivos. Além disso esses quadros de funcionários sofrem uma rotatividade maior tendo em vista que os mesmos nem sempre são fixos nos setores que são lotados.

Tabela 6 - Distribuição dos participantes por vínculo profissional

\begin{tabular}{lcc}
\hline Vínculo/Situação & Frequência & $\begin{array}{c}\text { Percentual } \\
(\%)\end{array}$ \\
Funcional & 62 & 62,6 \\
Efetivo & 16 & 16,2 \\
Contratado (Tercerizado) & 14 & 14,1 \\
Comissionado & 4 & 4,0 \\
Outro (não especificado) & 2 & 2,0 \\
Função Pública & 1 & 1,0 \\
Em branco & 99 & 100 \\
\hline Total & Fonte: elaborado pelos autores.
\end{tabular}

\subsection{Resultados da pesquisa de clima organizacional}

Neste tópico foram apresentados os principais resultados por dimensão. Por itens positivos entende-se as opções (concordo totalmente e concordo), como itens negativos (discordo totalmente e discordo) e como item neutro foi considerada a opção "não sei afirmar".

Cabe ressaltar que os itens foram construídos de maneira afirmativa, ou seja, a resposta ideal seria que todos respondessem por concordo ou concordo totalmente.

\subsubsection{Estrutura e ambiente físico}

Nesta dimensão os servidores avaliaram o ambiente de trabalho como agradável, possuidor de recursos necessários e facilitador para realizar as tarefas com mais de $70 \%$ os itens positivos.

Muito dessa avaliação positivo deve-se ao fato do mobiliário, estrutura e recursos de tecnologia da informação serem novos e devido ao suporte contrato para manutenção e correções necessárias.

\subsubsection{Cooperação e reciprocidade no ambiente de trabalho}

Essa dimensão não foi tão bem avaliada em sua plenitude, ou seja, em todos os itens pelos servidores. Os requisitos: "Os meus colegas de trabalho e eu formamos uma equipe integrada", "No meu trabalho sinto-me satisfeito(a) com a confiança que posso ter em meus 
colegas" e "Os meus colegas cooperam entre si" tiveram uma avaliação superior a 70\% nos itens positivos. Os itens "As relações entre as pessoas do meu setor são de amizade", "No meu setor, o clima de cooperação pode ser atribuído a um ambiente que estimula o trabalho em equipe" não alcançaram $70 \%$ de avaliação positiva.

Esse resultado pode demonstrar que há relações mais profissionais sendo estabelecidas, motivo pelo qual a amizade não é tão forte entre as pessoas, além disso pode coexistir uma falha da liderança na gestão das equipes fazendo com que o trabalho seja realizado de maneira mais individualizada e não haja muito o sentimento de "time" (MAAMARI; MAJDALANI, 2017).

\subsubsection{Participação nas decisões}

Essa dimensão também não foi bem avaliada, apenas um item teve $60 \%$ de avaliação positiva como se observa na tabela a seguir.

Esse resultado pode estar relacionado ao fato de que as pessoas participantes da pesquisa apresentam um perfil mais técnico e nem sempre participam das decisões da organização. Mol et al. (2010, p.61) ressalta que a participação coletiva é muito importante e "cria lações de pertencimento e relações duradouras". Um percentual a ser explorado nesta dimensão é o "Não sabe informar" que para um item quase chegou a 30\%. Isso demonstra que o servidor não tem bem claro como as críticas são recebidas pela chefia, ou seja, se é ou não bem aceita, há de se investigar neste caso como acontece os processos de acolhida da crítica bem como do seu tratamento.

Tabela 7 - Resultado consolidado por fator de avaliação da dimensão "Participação nas

\begin{tabular}{lccc}
\multicolumn{4}{c}{ decisões” } \\
\hline $\begin{array}{c}\text { Soma do } \\
\text { Percentual } \\
\text { Positivo }\end{array}$ & $\begin{array}{c}\text { Soma do } \\
\text { Percentual } \\
\text { Negativo }\end{array}$ & $\begin{array}{c}\text { Não sabe } \\
\text { informar }\end{array}$ \\
\hline $\begin{array}{l}\text { No meu setor somos } \\
\text { informados (as) sobre as } \\
\text { principais decisões }\end{array}$ & 62,6 & 27,3 & 10,1 \\
$\begin{array}{l}\text { No meu setor } \\
\text { deliberamos sobre as } \\
\text { principais decisões }\end{array}$ & 36,4 & 44,4 & 19,2 \\
$\begin{array}{l}\text { No meu setor somos } \\
\text { consultados (as) sobre as } \\
\text { principais decisões }\end{array}$ & 32,40 & 48,50 & 19,20 \\
$\begin{array}{l}\text { As sugestões e críticas } \\
\text { dos servidores são sempre } \\
\text { bem aceitas pelas chefias } \\
\text { superiores }\end{array}$ & 44,5 & & \\
\hline
\end{tabular}

Fonte: elaborado pelos autores.

\subsubsection{Reconhecimento de mérito}

Essa dimensão apesar de não ter sido tão bem avaliada alcançou avaliação positiva média de $68,7 \%$ demonstrando que há fragilidade no reconhecimento de mérito mas que uma parcela bem considerável concorda que o chefe elogia quando faz um bom serviço; que há satisfação com o interesse do chefe pelo serviço e por último a valorização dos servidores. 
A pesquisa não perguntou sobre o tipo de reconhecimento de mérito mais praticado as caberia uma investigação melhor quanto a esse item dentro do público pesquisado, até para entender os principais estímulos que as pessoas tendem a ser mais receptíveis e com isso se motivarem para aumentar com isso a satisfação no trabalho.

\subsubsection{Identificação com a instituição}

Essa dimensão teve uma avaliação mediana $(67,68 \%)$ em relação a percepção positiva dos servidores. No geral as pessoas têm identificação com trabalho que realizam, acreditam no objetivo da instituição, na sua contribuição para a sociedade e sentem orgulho de trabalharem onde trabalham.

Quando mais identificação as pessoas têm com a missão, visão e valores da instituição acredita-se que essas irão se importar mais com o trabalho atribuindo-lhe um valor pessoal maior. Além disso elas tendem a ser portar de maneira defender a imagem e a reputação da instituição.

\subsubsection{Controles}

Essa dimensão teve precisa ser analisada com bastante critério uma vez que sua lógica de resposta não segue o mesmo padrão das anteriores. Alguns itens devem ter resposta negativa e isso transmite a ideia de um bom clima organizacional pela percepção dos servidores.

O primeiro item "A minha instituição pressiona para que as tarefas sejam feitas dentro do prazo previsto", teve uma avaliação positiva de $72,8 \%$ e isso é bom uma vez que a organização deve zelar pelos prazos previstos na realização de cada tarefa. Isso é importante pois garante maior sinergia nos processos de trabalho uma vez que os prazos de entrega são cumpridos.

O segundo item "O chefe usa regras da instituição para punir os servidores" teve uma avaliação negativa de $53,5 \%$ e um percentual de $35,4 \%$ de "não sabe afirmar". Esses percentuais nos levam a refletir sobre como as chefias se baseiam para punir os servidores, se não pelas regras da instituição, fica a pergunta: quais regras estão sendo usadas para que as punições sem aplicadas? Não é prudente que essas regras sejam estabelecidas a partir do entendimento de cada gestor uma vez que isso torna a relação de trabalho muito pessoal e não profissional.

O terceiro item "Na minha instituição existe uma fiscalização permanente do chefe" teve uma avaliação negativa de $45,5 \%$ e isso é positivo uma vez que o chefe não deve ser visto como alguém que fiscaliza a realização de atividades, seu trabalho deve se concentrar no estabelecimento de diretrizes e suporte na realização das tarefas. Neste caso um percentual maior avaliação negativa é interessante para um bom clima organizacional.

Por fim, ressalta-se que apesar dos controles serem bons e por muitas vezes serem estabelecidos para dar maior estabilidade e segurança no processo o seu uso deve ser bem estruturado pois são capazes de afetar na percepção do clima organizacional.

\subsubsection{Autonomia funcional}

Essa dimensão teve um média de avaliação positiva de $63,15 \%$ o que representa uma percepção tendendo para boa, mas sendo necessário melhorar e ampliar a autonomia principalmente com a implantação de avaliação de desempenho consiste com perfil de cada servidor. A gestão do desempenho neste caso é bem vista uma vez que com a avaliação clara das entregas previstas para cada servidor é possível dar mais autonomia no seu dia a dia na condução do seu trabalho. 


\subsubsection{Conflitos}

Essa dimensão requer bastante atenção em sua análise uma vez que os itens nem sempre tem sua avaliação positiva como sendo a ideal.

O primeiro item "No meu setor não há conflitos" obteve uma média de 49,5\% de avaliação negativa, ou seja, consideraram que há conflito no local de trabalho. A literatura, principalmente aquelas que tratam das relações humanas costumam dizer que o conflito é positivo, no entanto ele deve existir na "quantidade" certa pois o excesso de conflito é prejudicial para o clima organizacional.

Já o segundo item "Os conflitos no meu setor são produzidos basicamente por invejas e intrigas" foi avaliado por $58,6 \%$ das pessoas como negativo, ou seja, os conflitos têm outra causa que merece melhor investigação que não a inveja e intriga.

Por fim, o terceiro item "Os conflitos em meu setor são devidos à falta de perspectivas profissionais para os servidores" a avaliação neste quesito ficou bem distribuída nas três opções sendo que o maior valor $(35,4 \%)$ foi avaliado como negativo, ou seja, a falta de perspectiva não é o que gera o conflito. Tratando-se da área pública já há uma perspectiva traçada para os servidores que são estabelecidos pelos planos de carreira estipulados em lei. Ressalta que esse plano se aplica apenas aos servidores efetivos e empregados públicos (terceirizados) que se submeteram a concurso público para ingresso específico em uma carreira.

\subsubsection{Remuneração e oportunidade}

Essa dimensão não foi bem avaliada, na média, pelos servidores uma vez que nenhum item alcançou nem mesmo $50 \%$ de avaliação positiva.

Apesar de algumas evidências serem apresentadas fica claro que os incentivos, neste caso pode-se entender estímulos, não estão sendo suficientes para que os servidores reconheçam como justa a sua remuneração frente ao trabalho desenvolvido bem como suas oportunidades de crescimento.

A área pública possui certa inflexibilidade no que diz especificamente a remuneração uma vez que há limite legal para gasto com pessoal além disso há grande impacto orçamentário e financeiro, no presente e no futuro toda a estrutura de remuneração dos servidores públicos.

\subsubsection{Perspectivas na instituição}

Essa dimensão foi bem avaliada no sentido de que as pessoas se vêm na instituição ao longo ao longo do tempo e aind a vem oportunidade dentro dela.

A formulação das duas questões não permite muita análise sendo assim para uma melhor investigação da "perspectiva na instituição" seria necessário pesquisar mais a fundo a dimensão. 


\section{CONSIDERAÇÕES FINAIS}

Chega-se ao fim deste trabalho acadêmico onde um longo caminho foi percorrido. Retoma-se neste capítulo os objetivos que eram:

- Mapear o perfil da amostra selecionada;

- Identificar quais variáveis tem melhor e pior avaliação na percepção do clima organizacional pelos servidores;

- Propor de forma resumida propostas de solução ou de melhoria que afetariam de forma positiva a percepção do clima organizacional pelos servidores;

Destes objetivos, destaca-se que os dois primeiros já foram cumpridos e apresentados ao longo dos capítulos anteriores.

Em relação ao último objetivo é possível inferir ao longo do texto algumas sugestões para que a percepção do clima melhore e mais do que isso, os servidores passem de fato serem satisfeitos com seu trabalho. Viu-se que isso não é simples pois envolve variáveis complexas da natureza humana de caráter bem individual e subjetivo. Os setores de RH das instituições não devem ser acomodar com os resultados obtidos nesta pesquisa, ou seja, a busca pela melhoria deve ser diária.

Faz-se necessário implantar e desenvolver algumas políticas de recursos humanos para sobretudo valorizar o capital intelectual existente dentro de cada órgão. Dentre essas políticas é vital pensar algo relacionado ao desenvolvimento contínuo das lideranças, estruturação de mecanismos de participação e construção coletiva, ampliação da sistemática de treinamento e desenvolvimento, reestruturação de um plano de incentivos (remuneração, promoção, oportunidades e benefícios) condizentes com a legislação e que ao mesmo tempo seja interessante para o servidor, valorização dos profissionais efetivos e ainda estabelecimento de mecanismos de participação dos servidores em fóruns e grupos de trabalho com o objetivo de discutir e propor novas práticas de recursos humanos.

Cabe ressaltar que a pesquisa sofreu com três limitações. A primeira delas foi o fato de que o instrumento de coleta foi um questionário estruturado não permitindo nenhuma resposta discursiva. Isso fez com que algumas nuances das questões não fossem captadas, o que dificultou no estabelecimento de proposta de melhoria. Além disso algum dos pesquisadores são servidor público e estiveram envolvido com a realidade organizacional um pouco das percepções e sugestões vieram das suas impressões enquanto sujeito participante do processo. A última limitação é que foi usado apenas um canal de coleta das percepções dos servidores. Seria mais enriquecedor para o trabalho, por exemplo, uma entrevista com alguns dos gestores das equipes bem como de representantes da área de $\mathrm{RH}$ dos órgãos envolvidos que foram selecionados para responder ao questionário. $\mathrm{O}$ trabalho em si não está acabado, ou seja, há espaço para novas pesquisas e estudos na área. Novas investigações servirão como base para implantação e avaliação de políticas de recursos humanos, especialmente no setor público que ainda é carente de análises e trabalhos como este.

Finaliza-se então esse trabalho com satisfação pelos resultados alçados e contribuição para que a gestão de pessoas seja aperfeiçoada com o tempo e os serviços prestados ao cidadão cada vez melhores. 


\section{REFERÊNCIAS}

ARAUJO, L.C.G; GARCIA, A.A. Gestão de Pessoas. São Paulo: Atlas, 2010.

BARÇANTE, Luiz Cesar. Ouvindo a voz do cliente interno. Rio de Janeiro: Qualitymark, 1995.

BERGAMINI, Cecília Whitaker. Motivação. 3. ed. São Paulo: Atlas, 1990.

CARBONE, Pedro Paulo et al. Gestão por competência e gestão do conhecimento. 3. ed. Rio de Janeiro: Editora FGV, 2009.

CHIAVENATO, Idalberto. Gestão de Pessoas. Rio de Janeiro: Elsevier, 2004.

CHUANG, E.; DILL, J.; MORGAN, J.C.; KONRAD, T.R. A configurational approach to the relationship between high-performance work practices and frontline health care worker outcomes. Health Serv. Res., 47 (1), p. 1460-1481, 2012.

FERREIRA, Patricia Itala. Clima organizacional e qualidade de vida no trabalho. Rio de Janeiro: LTC, 2014.

FRANÇA, Ana Cristina Lomongi. Comportamento organizacional: conceitos e práticas. São Paulo: Saraiva, 2006.

HASHEMI, J.; SADEQI, D. The relationship between job satisfaction and organizational climate: A case study of government departments in Divandarreh. World Sci. News, 45 (1), p. 373-383, 2016.

LI, W.; BHUTTO, T.A.; NASIRI, A.R.; SHAIKH, H.A.; SAMO, F.A. Organizational innovation: therole of leadership and organizational culture. International Journal of Public Leadership, Vol. 14No. 1, pp. 33-47, 2018.

LUZ, Ricardo. Gestão do Clima Organizacional. Rio de Janeiro: Editora Qualitymark, 2003.

MAAMARI, B. E.; MAJDALANI, J.F. Emotional intelligence, leadership style and organizational climate. International Journal Organ. Anal., 25 (2), p. 327-345, 2017.

MARRAS, Jean Pierre. Administração de Recursos Humanos: do operacional ao estratégico1. 14. ed. São Paulo: Saraiva, 2011.

MENEZES, Igor Gomes; GOMES, Ana Cristina Passos. Clima organizacional: uma revisão histórica do construto. Psicologia em Revista, v. 16, n. 1, p. 158-179, 2010. Disponível em: $<$ http://periodicos.pucminas.br/index.php/psicologiaemrevista/article/view/P.16789563.2010v16n1p158>. Acesso em 09/02/2015 
MOL, et. al. Clima organizacional na administração pública: um estudo da Secretaria de Estado de Administração e Recursos Humanos do Rio Grande do Norte. Rio de Janeiro: Editora FGV, 2010.

NOBREGA, Fernanda de Araújo; SÁ, Maria Auxiliadora Diniz. Práticas de Recursos Humanos e sua Influência na Valorização Humana no Trabalho: realidade ou apenas discurso? XXXIV Encontro Nacional dos Pós Graduados em Administração. Rio de Janeiro, 2010. Anais.

Portal Institucional da Secretaria de Estado de Planejamento e Gestão. Governo de Minas. Disponível em: <http://www.planejamento.mg.gov.br> Acesso em 07/02/2015.

Portal Institucional da Secretaria de Estado de Saúde. Governo de Minas. Disponível em: $<$ http://www.saude.mg.gov.br> Acesso em 09/02/2015.

PRIYANKARA, H.P.R.; LUO, F.; SAEED, A.; NUBUOR, S.A.; JAYASURIYA, M.P.F. How Does Leader's Support for Environment Promote Organizational Citizenship Behaviour for Environment? A Multi-Theory Perspective. Sustainability, 10 (2), 271-280, 2018.

PUCMINAS. Pró-Reitoria de Graduação. Sistema de Bibliotecas. Padrão PUC Minas de normalização: normas da ABNT para apresentação de teses, dissertações, monografias e trabalhos acadêmicos / Elaboração Helenice Rêgo dos Santos Cunha. 9. ed. rev. ampl. atual. Belo Horizonte: PUC Minas, 2011.93 p. : Il.

RIZZATTI, G. Categorias de análise de clima organizacional em universidades federais brasileiras. Florianópolis, 2002. Tese (Doutorado). Departamento de Engenharia de Produção e Sistemas, Universidade Federal de Santa Catarina. Disponível em: <http://repositorio.ufsc.br/handle/123456789/84206> Acesso em 10/02/2015

TEIXEIRA, Gilnei Mourão et al. Gestão Estratégica de Pessoas. 2. ed. Rio de Janeiro: Editora FGV, 2010.

VENTURA, Magda Maria. O estudo de caso como modalidade de pesquisa. Revista da Sociedade de Cardiologia do Estado do Rio de Janeiro, Rio de Janeiro, v. 20, n. 5, p. 383386, 2007. set./out. Disponível em: <http://sociedades.cardiol.br/socerj/revista/2007_05/a2007_v20_n05_art10.pdf>. Acesso em: $10 / 02 / 2015$

VERGARA, Sylvia Constant. Gestão de Pessoas. 11. ed. São Paulo: Atlas, 2012.

YIN, R. K. Estudo de caso: planejamento e métodos. 3. ed. Porto Alegre: Bookman, 2001. 